\title{
“Kissing Spinal Disc Herniations”, An Atypical Pattern of Lumbar Disc Herniation: A Case Report
}

Daniele Vanni ${ }^{1 *}$, Renato Galzio ${ }^{2}$, Anna Kazakova ${ }^{3}$, Vincenzo Salini ${ }^{1}$ and Vincenzo Magliani ${ }^{3}$

${ }^{1}$ Orthopaedic and Traumatology Department, “G. D'Annunzio” University, Chieti, Italy

${ }^{2}$ Department of Neurosurgery, "L'Aquila” University, L'Aquila, Italy

${ }^{4}$ Department of Vertebral Surgery, "S.S. Annunziata" Hospital, Chieti, Italy

\begin{abstract}
Introduction: The purpose of this work is to report a rare variation of lumbar disc herniation (LDH) not previously reported in the literature.

Case presentation: We describe this single case of young Caucasian male (23 years) afflicted with a double migrated LDH and we examine the problems associated both with the diagnostic aspects both with the therapeutic approach. According to our knowledge, no cases of simultaneous cranial and caudal migration of two adjacent LDH, with the consequent compression of the same spinal root is reported in literature. Specifically, the caudal migration concerned the fragment of the herniation of the level above, while the cranial migration affected the herniation of the level below. Thus these two fragments were placed towards one another, compressing the same spinal root. This atypical pattern of discs-root conflict was defined "kissing herniations".

Conclusions: Although LDH generally does not provide for the migration of a fragment to the levels above or below, in $10 \%$ of the cases this might happen, but it is a single one, ordinarily. Infact a case of a double and convergent migration of two different fragments have never been reported before in the literature. The analysis of this case can help to better understand how a degenerative disc disease can evolve. Especially the analysis of this case allows understanding how the stresses of the discs can focus in some defined areas of the vertebral bodies and thus they can determine the suffering of the discs themselves. This type of case has an impact on various disciplines, including: orthopedics, neurosurgery, spine surgery, rheumatology, physiatry, neurology, general medicine.
\end{abstract}

Keywords: Lumbar disc; Spinal root; Kissing herniations

\section{Introduction}

The purpose of this work is to report a rare variation of lumbar disc herniation (LDH) not previously reported in the literature. Our aim is to report this unique case of double herniation, resulting in a double disc-root conflict, in a young patient. The goal is to create a moment of comparison and discussion about the etiology of disc degeneration and its consequences, but also to evaluate the type of surgical approaches usable in cases such this, that is unique and complex. This case is "a rarity" since there is no comparable medical cases described in the literature. In our opinion it is mandatory to introduce the new concept, never explained before, of "kissing herniations", that is a dual root-conflict resulting from a double and convergent fragment migration.

\section{Case Presentation}

A 23 years caucasian male arrived at the emergency department due to a low back pain and a right lower limb ache. The patient did not report any recent or past trauma. A radiograph of the lumbosacral spine, routinely performed, did not show any osteostructural anomalies. The physical examination showed ache of lumbar paraspinal muscles and pain in the right fifth lumbar (L5) root territory (visual analogue scale -VAS- 6). Lasegue test and straight leg raising test were positive at $15^{\circ}$. Sciatic Valleix points were positive at right lower limb. Dysesthesia and hypoesthesia were recognizable in the right L5 and partially in the right first sacral S1 root territory. A deficit of extensor proprius halluci and extensor digitorum communis, a complete hypovalidity of posterior tibialis and a partial alteration of Achilles reflex were assessed. This clinical presentation was compatible with a diagnosis of a lumbar disc herniation (LDH) and a complete L5 and a partial S1 right spinal roots compression. A lumbar magnetic resonance imaging (MRI), showed:
- L4-L5 and L5-S1 degenerative disc disease, (grade III according to Pfirrmann classification) [1].

- L4-L5 right disc herniation with caudal migration of the fragment and L5 spinal root compression (Figures 1-5).

- L5-S1 right disc herniation with cranial migration of the fragment, complete L5 and partial S1 spinal roots compression (Figure 1-6).

Subsequently, an electromyogram (EMG) showed evidence of complete radiculopathy of the L5 right spinal root and a partial radiculopathy of the $S 1$ spinal root.

Finally after 5 days, a double right microdiscectomy L4-L5 and L5S1 by translaminar approach was performed.

After the surgery, the improvement in pain was almost immediate. The patient gradually recovered the motor functions, initially compromised ( $80 \%$ within the first month). The patient was able to go back to work at the day 30 and he came back to play non-competitive sports activities at day 60 after surgery.

We have obtained consent to publish from the participant to report

*Corresponding author: Daniele Vanni MD, Orthopaedic and Traumatology Department, "G.d'Annunzio" University, Chieti and Department of Vertebral Surgery, "S.S. Annunziata" Hospital, Vestini Street, Chieti, Italy, Tel: +390871358263; Fax: +390871.560082; E-mail: danielevannimd@libero.it

Received January 11, 2016; Accepted January 20, 2016; Published January 22 2016

Citation: Vanni D, Galzio R, Kazakova A, Salini V, Magliani V (2016) "Kissing Spinal Disc Herniations", An Atypical Pattern of Lumbar Disc Herniation: A Case Report. J Spine 5: 283.doi:10.4172/2165-7939.1000283

Copyright: $\odot 2016$ Vanni D, et al. This is an open-access article distributed under the terms of the Creative Commons Attribution License, which permits unrestricted use, distribution, and reproduction in any medium, provided the original author and source are credited. 

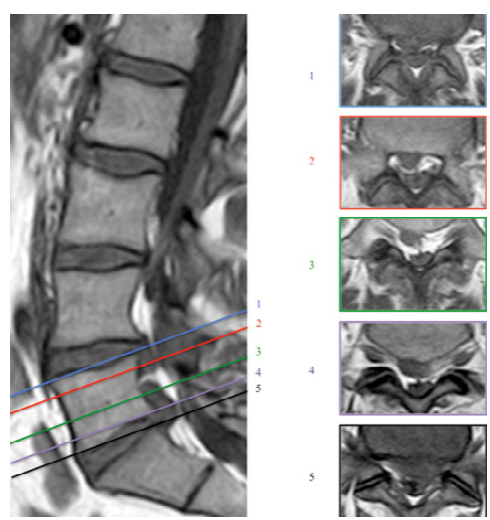

Figure 1: Preoperative nuclear magnetic resonance short T2 weighted turbo spin-echo (overview).

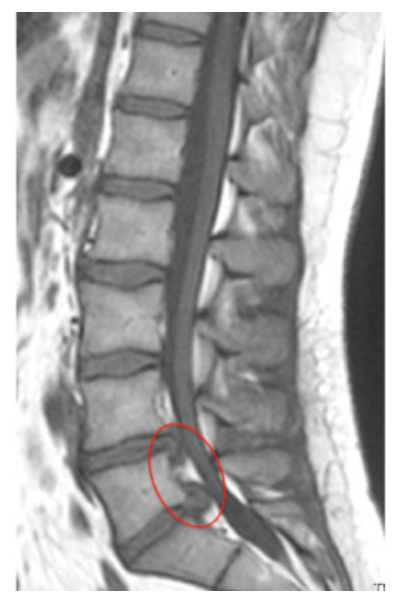

Figure 2: Preoperative nuclear magnetic resonance short T1 weighted turbo spin-echo (sagittal view).

individual patient data. None of the authors have any competing interests in the manuscript.

\section{Discussion}

The prevalence of symptomatic LDH is around 1-3\% [2]. The highest prevalence is among people aged $30-50$ years, with a male: female ratio of 2: 1.6 [2]. In people aged between 25 and 55 years, about $95 \%$ of herniated discs occur at the L4-L5 or L5-S1 level while in people over 55 years of age, disc herniation is more common above the L4-L5 level $[3,4]$.

The guideline of the Washington State Department of Labor and Industries identifies four criteria that must coexist to establish the elective surgical indication [5]:

- Failure of conservative therapy performed for at least four weeks (according to Netherlands Consensus Conference -CBO- 6 weeks [6])

- Sensory symptoms in the dermatome of relevance.

- Objective signs of sensory or motor deficits or reflexes alterations in the dermatome of relevance or EMG positive.

- Conformity between imaging and clinical presentation.

The standard surgical technique is the microdiscectomy, via interlaminar approach, described by Caspar. This type of approach is possible only in case of LDH not associated with migration of the fragment. In such cases, the standard interlaminar microsurgical approach cannot be performed without laminectomies and partial or total facetectomies, due to the risk of iatrogenic instability [7].

Although LDH generally occurs without migration of the fragment to the level above or below, in $10 \%$ of the cases this might happen [3] but it is a single one, ordinarily. Infact a case of a double and convergent migration of two different fragments have never been reported before in the literature. For these reasons, this single and atypical pattern of discs-root conflict was defined "kissing herniations". In case of cranially or caudally extruded LDH [8] a minimally invasive approach able to respect the anatomy and the biomechanics of the spine represents the most appropriate technique [4].

The translaminar approach is the only "tissue-sparing" technique viable in cases of cranially or caudally migrated LDH encroaching on the exiting nerve root in the preforaminal zones $[4,9,10]$ for the levels above L2-L3, and in the preforaminal and foraminal zones, for the levels below L3- L4 (L5-S1 included, if a total microdiscectomy is not necessary) $[4,10]$.

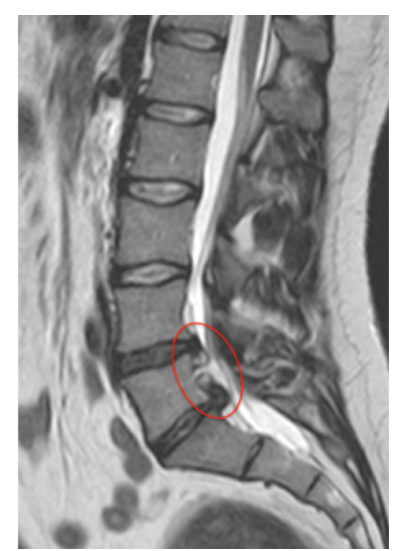

Figure 3: Preoperative nuclear magnetic resonance short T2 weighted turbo spin-echo CLEAR (sagittal view).

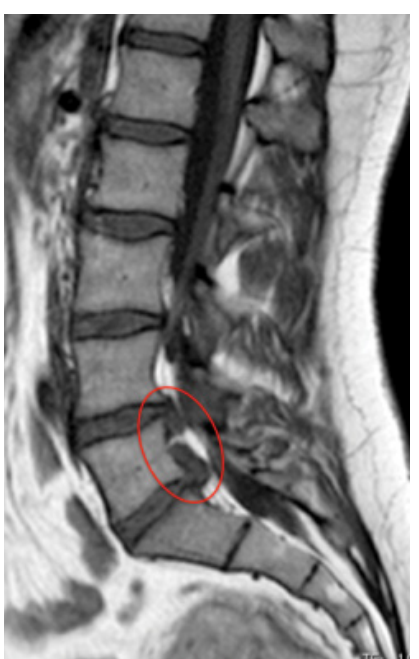

Figure 4: Preoperative nuclear magnetic resonance short T1 weighted turbo spin-echo CLEAR (sagittal view). 


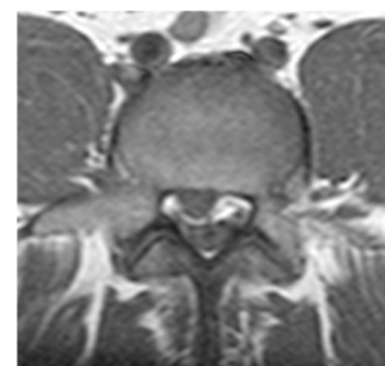

Figure 5: L4-L5 right disc herniation with caudal migration of the fragment (preoperative nuclear magnetic resonance short T2 weighted turbo spinecho, axial view).

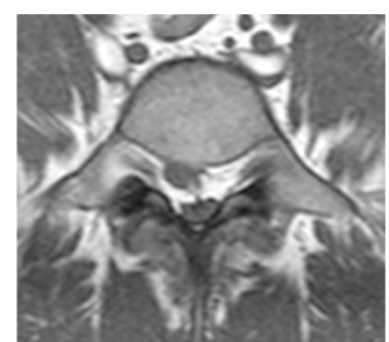

Figure 6: L5-S1 right disc herniation with cranial migration of the fragment (preoperative nuclear magnetic resonance short T2 weighted turbo spinecho, axial view)

This approach is associated with a lower postoperative pain and a faster recovery times [4]. In this case a microdiscectomy L4-L5 and L5-S1 by translaminar approach was performed, avoiding both the laminectomy and the flavectomies. Thus both the surgical time and the risk of bleeding were reduced, but this approach allows decreasing the risk of fibrous adhesions and recurrences, which is even more important with young patients.

\section{Conclusion}

To our knowledge, founded on a review of the literature, other cases of simultaneous, ipsilateral and convergent migration of two different hernial fragments, belonging to two contiguous disk and migrated in the opposite direction, one towards the other, resulting in a double compression of the same nerve root, have never been described until now $[11,12]$.

\section{Consent}

Written informed consent was obtained from the patient for publication of this case report and any accompanying images. A copy of the written consent is available for review by the Editor-in-Chief of this journal.

\section{Competing Interests}

The authors declare that they have no competing interests.

\section{References}

1. Pfirrmann CW, Metzdorf A, Zanetti M, Hodler J, Boos N (2001) Magnetic resonance classification of lumbar intervertebral disc degeneration. Spine (Phila Pa 1976) 26: 1873-1878.

2. Kamper SJ, Ostelo RW, Rubinstein SM, Nellensteijn JM, Peul WC, et al. (2014) Minimally invasive surgery for lumbar disc herniation: a systematic review and meta-analysis. Eur Spine J 23: 1021-1043.

3. Ma D, Liang Y, Wang D, Liu Z, Zhang W, et al. (2013) Trend of the incidence of lumbar disc herniation: decreasing with aging in the elderly. Clin Interv Aging 8: 1047-1050.

4. Vanni D, Sirabella FS, Guelfi M, Pantalone A, Galzio R, et al. (2015) Microdiskectomy and translaminar approach: minimal invasiveness and flavum ligament preservation. Global Spine J 5: 84-92.

5. Criteria for entrapment of a single nerve root (1990) Washington State Department of Labour and Industries, Washington State Medical Association - Medical Speciality Society.

6. Consensus Het Lombosacrale Radikulaire Syndroom, 1995.

7. Abdullah AF, Wolber PG, Warfield JR, Gunadi IK (1988) Surgical management of extreme lateral lumbar disc herniations: review of 138 cases. Neurosurgery 22: 648-653.

8. Faulhauer K, Manicke C (1995) Fragment excision versus conventional disc removal in the microsurgical treatment of herniated lumbar disc. Acta Neurochir (Wien) 133: 107-111.

9. Reulen HJ, Müller A, Ebeling U (1996) Microsurgical anatomy of the latera approach to extraforaminal lumbar disc herniations. Neurosurgery 39: 345-350.

10. Tessitore E, de Tribolet N (2004) Far-lateral lumbar disc herniation: the microsurgical transmuscular approach. Neurosurgery 54: 939-942.

11. Branam BR, Stambough JL (2002) Atypical lumbar disc herniation: a case report. Spine J 2: 224-226.

12. Elgamri A, Sami A, Aqqad A, Hilmani S, Ibahioin K, et al. (2009) Posterior migration of a lumbar disc herniation as a cause of cauda equina syndrome. $J$ Radiol 90: 731-733. 